\title{
A Multi-Site Cross-Sectional Study of Anxiety Symptoms and the Associated Factors Among Chinese Drug Users Undergoing Compulsory Detoxification Treatment
}

\author{
Xiaoshi Yang ${ }^{1 *}$, Carrie Kovarik ${ }^{2}$, Yuke Wang ${ }^{3}$ and Shenshui Yu ${ }^{3}$ \\ ${ }^{1}$ Department of Social Medicine, School of Public Health, China Medical University, Shenyang, China, ${ }^{2}$ Department of \\ Dermatology, University of Pennsylvania, Philadelphia, PA, United States, ${ }^{3}$ Liaoning Juvenile's Compulsory Drug Detention \\ Center, Shenyang, China
}

OPEN ACCESS

Edited by:

Wulf Rössler,

Charité - Universitätsmedizin

Berlin, Germany

Reviewed by:

Jochen Mutschler,

Private Clinic Meiringen, Switzerland

Yan-Hong Huang,

Shenyang Women and Infants

Hospital, China

*Correspondence:

Xiaoshi Yang

xsyang@cmu.edu.cn

Specialty section: This article was submitted to

Public Mental Health,

a section of the journal

Frontiers in Public Health

Received: 04 February 2020

Accepted: 18 February 2021

Published: 11 March 2021

Citation:

Yang $X$, Kovarik C, Wang Y and Yu S (2021) A Multi-Site Cross-Sectional Study of Anxiety Symptoms and the Associated Factors Among Chinese Drug Users Undergoing Compulsory

Detoxification Treatment.

Front. Public Health 9:524068.

doi: 10.3389/fpubh.2021.524068
Compulsory drug detoxification treatment (CDT) is currently the major drug rehabilitation modality in China, and drug users often suffer from extraordinary levels of stress during CDT, leading to a high prevalence of anxiety symptoms. This study assesses anxiety symptoms of the drug users undergoing CDT and explores the associated factors. A cross-sectional study with cluster sampling was conducted in three cities in Liaoning Province of Northeast China. Nine hundred CDT drug users were interviewed face-to-face with Chinese questionnaires. Hierarchical multiple regression (HMR) analysis was conducted to explore the factors associated with anxiety symptoms. The prevalence of anxiety symptoms among the CDT drug users was substantially high (33.2\%). HMR analysis indicated perceived stress and characteristics of drug use such as types of drugs, were the most important contributors to anxiety symptoms. Optimism (LOT-R) played a protective role in reducing anxiety symptoms in this population. Anxiety symptoms of drug users undergoing CDT were present in a significant proportion of the CDT population. Optimism is a protective factor which could attenuate the detrimental effects of perceived stress on anxiety symptoms and potentially improve treatment outcomes.

Keywords: anxiety symptoms, perceived stress, optimism, drug users, compulsory detoxification treatment

\section{INTRODUCTION}

Illicit drug use has spread dramatically in China since the 1980 's, becoming a critical public health problem. According to China's National Narcotics Control Commission 2016 Annual Report on Drug Control in China, synthetic drugs such as methamphetamine and other amphetamine-type stimulants have surpassed heroin to become the most abused drugs in China. Abuse of various new psychoactive substances, such as ketamine, is also increasingly prevalent. By the end of 2014, the number of registered drug users in China reached 2.96 million (compared to 70,000 in 1990) (1).

Drug addiction impacts the individual user, their families, and society, with loss productivity and revenue, engagement in high risk behaviors, transmission of communicable diseases, increase in criminal behavior, increase in health care expenditures, and stress on interpersonal relationships. Given the exponential rise in drug use over the past several decades and the impact on a 
significant population in China, the 2008 Anti-Drug Law of China created a new drug detoxification system. Compulsory drug detoxification treatment (CDT) is currently the major drug rehabilitation modality in China (2). Drug addicts who have refused community based rehabilitation, have failed to maintain abstinence, or have been arrested for having a severe drug addiction are sent to this 1-3 year program, which is managed by the Ministry of Justice $(2,3)$. The CDT, which restricts drug users' daily lives and freedom, is different from that in Western countries. It is a compulsory administrative measure and is issued by the public security bureau and enforced by the judicial administrative bureau.

The drug users on CDT are a vulnerable population, exposed to numerous inner conflicts, feelings of isolation, lack of support, and hardships of daily life. The struggles and stressful experiences due to this treatment not only bring about psychological and physical distress, but also result in the high levels of perceived stress, which is the degree to which situations in one's life are appraised as stressful. In addition, the drug users are more susceptible to negative feelings, such as helplessness and hopelessness, or feelings of guilt in adverse situations which could contribute to future relapse. Previous research has reported that drug users have an increased prevalence and comorbidity of psychiatric disorders, such as depression and anxiety as compared to the general populations, which also need to be addressed during treatment (4-6).

Psychiatric comorbidity is a major issue that should be addressed when treating patients with substance abuse in order to maintain abstinence. A recent study by Dong et al. from both compulsory and voluntary treatment centers in China shows significant differences in the psychiatric comorbidity, based on the drug of choice, with methamphetamine-dependence related to higher rates of psychotic disorders and heroin-dependence related to higher rates of substance-induced mood disorders $(7,8)$. Previous research by Yin et al. in one of China's methadone maintenance treatment centers indicated a high prevalence of anxiety among drug users in treatment $(18.4 \%)$ and a significant number with co-occurring depression (14.2\%) (9).

The transactional stress model theory proposed by Lazarus and Folkman (10) can be applied to explain how major life events and daily challenges impact mental health. This process is influenced by cognitive appraisal, including assessing threats, and coping with stress (11-14). The commonly used transactional stress model indicated that cognitive appraisal could affect the process of life events and coping styles when tacking with difficulties, and made significant contribution to the individual's mental health among the drug users. CDT is a major life event for the drug user and brings about tremendous challenges in their daily life and psychological reaction, which may have an detrimental impact on mental and emotional well-being, placing them at risk for psychological disorders. Moreover, perceived stress can result in physiologic or psychological impairment that puts them at risk for anxiety. Based on previous studies (15), higher levels of perceived stress negatively affect drug users' psychological health, often correlating with symptoms of anxiety and depression (1618).
However, the adoption of positive psychological capabilities has been found to be inversely related to anxiety among drug users (19). The positive capabilities, such as having an optimistic attitude, appear to have positive effects on the psychological wellbeing and could attenuate the prevalence of anxiety symptoms. Optimism is a positive psychological resource with a tendency to expect favorable outcomes about the future (20). It has been found to be associated with more active coping strategies, lower levels of psychological distress, health-enhancing behavior, and improved outcomes in drug rehabilitation. In one study, the extent of professed optimism about one's future distinguished between those showing positive and negative outcomes in drug rehabilitation. In addition, optimism and pessimism were the only psychological measure to serve as a predictor of post-treatment drug use (21). However, studies evaluating the influences of positive psychological resources, such as optimism, on drug users in treatment are underrepresented, and relevant studies have not been conducted among the CDT drug users in China.

Despite the availability of health care services, there are still barriers to address the psychological needs of CDT drug users in China. This study, therefore, evaluates the prevalence of anxiety symptoms experienced by drug users who are in CDT and explore the predictors of anxiety symptoms. The findings from this study will give effective directions to deliver necessary health care services in order to improve mental health and psychological well-being among drug users undergoing CDT.

\section{METHODS}

\section{Sample and Data Collection}

A cross-sectional study with clustering sampling was conducted in three cities in Northeast China (Shenyang, Dalian and Yingkou) from February 2016 to October 2016. Eligible subjects were those undergoing CDT in rehabilitation, at least 18 years old and without diagnosed severe independent psychiatry diseases, including anxiety and panic disorders, bipolar disorder, depression, eating disorders, and schizophrenia. This study was collaborated with Liaoning Juveniles Compulsory Drug Detention and Detoxification Center and Centers for Disease Prevention and Control (CDC) of Dalian and Yingkou. A total of 900 CDT drug users who were screened for eligibility and met the inclusion criteria were enrolled in this study. Trained correctional officers conducted face-to-face interviews using the study questionnaires at the project office with the 793 CDT participants who completed the study. The characteristics (age, sex, characteristics of drug use and rehabilitation) of the included participants were similar to those of the 107 CDT drug user who were excluded.

\section{Ethics Statement}

Written informed consent was obtained prior to enrollment from each participant. Face-to-face interviews lasting for $\sim 20$ 30 min were conducted by trained surveyors at the project office where privacy was well-protected. The procedures conformed to ethical standards and approved by the Committee on Human Experimentation of China Medical University. 


\section{Measures}

\section{Assessment of Anxiety Symptoms}

Anxiety symptoms were measured with the Zung Self-Rating Anxiety Scale (SAS) (22), which is composed of 20 items with four possible responses: (1) never, (2) rarely/sometimes, (3) frequently, and (4) always. Each item was scored on a 4-point Likert according to severity of anxiety disorder. The raw score was standardized according to the formula: standard score $=$ int (1.25* raw score). According to the Chinese norm, when a score exceeded 50, it was determined that the person suffered from anxiety symptoms (23). Higher scores indicate greater perceived anxiety symptoms.

\section{Demographic Characteristics of the Participants}

Demographic characteristics included age, marital status (never married, married or others which included widowed, divorced or separated), sex, level of education, and monthly income. Level of education was classified as "primary school or below," "junior high school," or "senior high school or above." Monthly income was categorized as " $\leq 2,000$ yuan," "2,001-3,000 yuan," "3,0015,000 yuan," or " $\geq 50,001$ yuan."

\section{Characteristics of Drug Use}

Characteristics of drug use consisted of types of drugs, method of drug delivery, provision source of drugs, frequency of drug use, and duration of drug use. Types of drugs was categorized as "opioids," including heroin, morphine and others, "synthetic," such as ice and ecstasy or "combination." Method of drug delivery was divided into "mouth and nose inhalation," "intravenous drug use," and "other methods." Provision source of the drugs included "provided from partners/friends," "provided from drug dealers," and "both sources." Frequency of drug use was classified as "more than once a day once/day," "once a week once every other week," and "once a month occasionally." Duration of drug use was categorized as "<1year," "1-2 years," " $2-5$ years," or " $\geq 5$ years."

\section{Characteristics of Rehabilitation of CDT}

Characteristics of the current rehabilitation of CDT included degree of willingness of drug abstention, number of times of CDT, and period of time of current CDT (how long they had been in the current period of CDT). Degree of willingness of drug abstention was classified as "extreme," "slight," and "none." Number of times of CDT was categorized as "one time," "two times," and "three times or more." Period of the current CDT was categorized as " $<3$ months," "3-12 months," "12-18 months," and " $\geq 18$ months."

\section{Measurement of Perceived Stress}

The Perceived Stress Scale (PSS) was employed to assess the perceived stress (24), which consisted of ten items that involved questions measuring the individual's feelings and thoughts in last month. The responses for each item ranged from 0 (never) to 5 (very often). Answers were summarized to create an overall score ranging from 0 to 40 , with higher scores indicating the higher levels of perceived stress. The Cronbach's alpha coefficient for this scale in this study was 0.949 .

\section{Measurement of Optimism}

Optimism was assessed with the Life Orientation Test Revised (LOT-R) (25), which was devised to measure individual differences in generalized optimism vs. pessimism and had been validated and widely used in many countries, including United States, Brazil, Germany, Norway and China (26). The LOT-R consisted of 10 items, which were rated on a 5-point Likert scale ranging from 1 (I strongly agree) to 5 (I strongly disagree), while the items reflecting pessimism were scored from 5 to 1 . Total scores were calculated by summing the three positively worded items and three negatively worded items that were reversely coded, ranging from 6 to 30, with lower scores indicating higher levels of optimism. The Cronbach's alpha coefficient was 0.707 in this study.

\section{Statistical Analysis}

The distributions of SAS scores among the categorical variables were depicted by T-tests and one-way ANOVA. Pearson's correlation was used to assess the correlations between SAS scores and the related factors. All the continuous variables were standardized in order to avoid multicollinearity before performing the regression analysis (27). Hierarchical multiple regression (HMR) analysis was employed to test the incremental variance by using a set of independent variables. The SAS scores were used as dependent variables, with the independent variables being entered in the following steps: Step 1: demographic characteristics of the drug user; Step 2: characteristics of drug use; Step 3: characteristics of current rehabilitation; Step 4: perceived stress and Step 5: optimism. Standardized parameter estimates (the standardized $\beta$ ) were used in order to make comparisons of the magnitudes of the associations across independent variables. The fit of the model was assessed with the $R^{2}$-value. Statistical analyses were conducted using SPSS 17.0, and a twotailed probability value of $<0.05$ was considered to indicate statistical significance.

\section{RESULTS}

\section{Description of the Participants}

The valid response rate was $88.11 \%$ in this study. The basic characteristics of CDT drug users are provided in Table 1. The participants' average age was $33.34 \pm 8.86$ years old (ranging from 18 to 63 years old). Most (60.2\%) of the participants had a maximum education level of junior high school. There were 410 drug users addicted to synthetic drugs (51.7\%), 138 addicted to opioid type drugs (17.4\%), and 245 drug users (30.9\%) addicted to both types of drugs. The majority of drugs were delivered through mouth and nose inhalation (61.7\%). The duration of drug use varied, but a slight majority had been using for 2 years or less $(56.2 \%)$.

More than half of the drug users expressed extreme willingness to recover from drug addiction, while 28.8 and $15.5 \%$ of the drug users had slight to no willingness. Almost $37 \%$ of the drug users had received CDT more than once. Most participants in current CDT had been present for $<3$ months $(37.7 \%)$, while only a small proportion had been there more than 18 months (19.3\%). 
TABLE 1 | Baseline characteristics of study participants and distribution of anxiety symptoms $(n=793)$.

\begin{tabular}{|c|c|c|c|}
\hline & $\mathbf{n}$ & $\%$ & SAS \\
\hline \multicolumn{4}{|l|}{ Age } \\
\hline$<30$ & 328 & 41.4 & $43.99 \pm 10.962$ \\
\hline 30-35 & 175 & 22.1 & $44.32 \pm 13.010$ \\
\hline$>35$ & 290 & 36.5 & $47.19 \pm 11.446^{\star \star}$ \\
\hline \multicolumn{4}{|l|}{ Sex } \\
\hline Men & 373 & 47 & $45.00 \pm 11.937$ \\
\hline Women & 420 & 53 & $45.44 \pm 11.492$ \\
\hline \multicolumn{4}{|l|}{ Marital status } \\
\hline Never married & 337 & 42.5 & $44.84 \pm 11.748$ \\
\hline Married & 259 & 32.7 & $44.55 \pm 10.660$ \\
\hline Other & 197 & 24.8 & $46.8 \pm 12.785$ \\
\hline \multicolumn{4}{|l|}{ Levels of education } \\
\hline Primary school or below & 128 & 16.1 & $50.14 \pm 10.762^{\star \star}$ \\
\hline Junior high school & 477 & 60.2 & $44.12 \pm 11.268$ \\
\hline Senior high school or above & 188 & 23.7 & $44.72 \pm 12.563$ \\
\hline \multicolumn{4}{|l|}{ Monthly income (yuan) } \\
\hline$<2,000$ & 240 & 30.3 & $45.48 \pm 12.031$ \\
\hline $2,001-3,000$ & 261 & 32.9 & $43.40 \pm 12.858$ \\
\hline $3,001-5,000$ & 187 & 23.6 & $46.75 \pm 9.982^{\star}$ \\
\hline$\geq 5,001$ & 105 & 13.2 & $46.54 \pm 10.176^{\star}$ \\
\hline \multicolumn{4}{|l|}{ Types of drugs } \\
\hline Synthetic drugs & 410 & 51.7 & $47.79 \pm 11.148^{\star \star}$ \\
\hline Opioids & 138 & 17.4 & $37.36 \pm 9.747$ \\
\hline Combination & 245 & 30.9 & $45.39 \pm 11.698^{*}$ \\
\hline \multicolumn{4}{|l|}{ Methodof drug delivery } \\
\hline Mouth and nose inhalation & 489 & 61.7 & $47.20 \pm 11.460^{\star \star}$ \\
\hline Intravenous drug use & 151 & 19.0 & $40.85 \pm 11.774$ \\
\hline Other methods & 153 & 19.3 & $43.28 \pm 10.923^{\star}$ \\
\hline \multicolumn{4}{|l|}{ Duration of drug use } \\
\hline$<$ 1year & 231 & 29.1 & $39.53 \pm 11.291$ \\
\hline $1-2$ years & 215 & 27.1 & $47.67 \pm 11.134^{\star}$ \\
\hline $2-5$ years & 196 & 24.7 & $46.27 \pm 10.213^{\star}$ \\
\hline$\geq 5$ years & 151 & 19.0 & $49.14 \pm 11.803^{\star \star}$ \\
\hline \multicolumn{4}{|l|}{ Frequency of drug use } \\
\hline More than once a day-once/day & 334 & 42.1 & $48.54 \pm 11.351^{\text {** }}$ \\
\hline Once a week-once every other week & $<190$ & 24.0 & $46.14 \pm 10.491^{*}$ \\
\hline Once a month-occasionally & 269 & 33.9 & $40.48 \pm 11.392$ \\
\hline \multicolumn{4}{|l|}{ Provision source of the drugs } \\
\hline Provided from Drug dealers & 160 & 20.18 & $49.55 \pm 11.00$ \\
\hline Provided from Partners/Friends & 145 & 18.28 & $46.97 \pm 9.70$ \\
\hline Both sources & 349 & 44.01 & $40.91 \pm 11.79^{\star \star}$ \\
\hline Other sources & 139 & 17.53 & $49.29 \pm 10.42$ \\
\hline \multicolumn{4}{|l|}{ Period of time of current CDT } \\
\hline$<3$ months & 299 & 37.7 & $39.88 \pm 10.951$ \\
\hline 3-12 months & 170 & 21.4 & $49.00 \pm 11.365^{\star \star}$ \\
\hline $12-18$ months & 171 & 21.6 & $49.06 \pm 11.233^{\star \star}$ \\
\hline 18 months & 153 & 19.3 & $47.24 \pm 10.022^{* \star}$ \\
\hline \multicolumn{4}{|l|}{ Number of times of CDT } \\
\hline One time & 500 & 63.1 & $43.91 \pm 12.263$ \\
\hline Two times & 166 & 20.9 & $47.30 \pm 10.521^{\text {** }}$ \\
\hline Three times or more & 127 & 16 & $47.74 \pm 10.035^{\star \star}$ \\
\hline \multicolumn{4}{|l|}{ Willingness of drug abstention } \\
\hline Extreme & 442 & 55.7 & $42.20 \pm 11.206$ \\
\hline Slight & 228 & 28.8 & $48.23 \pm 11.365^{\star}$ \\
\hline None & 123 & 15.5 & $50.59 \pm 10.723^{\star \star}$ \\
\hline
\end{tabular}

"Significant at the 0.05 level (two-tailed); " Significant at the 0.01 level (two-tailed). $C D T$, compulsory detoxification treatment.

\section{Anxiety Symptoms of the CDT Drug Users}

Table 1 shows the distributions of anxiety symptoms among participants. The prevalence of anxiety symptoms among drug users undergoing CDT was $33.2 \%$ ( $S A S \geq 50$ ). The study found that drug users 35 years and older, with only a primary school education, addicted for more than 5 years, used drugs at least once per day, and used synthetic drugs had greater perceived anxiety symptoms. There was a significant difference between the anxiety symptoms of mouth and nose inhalation and intravenous drug use $(P<0.01)$, with those preferring inhalation methods reporting greater perceived anxiety symptoms. Drug users whose current CDT has lasted longer than 3 months exerted greater SAS anxiety scores than those who had been present for $<3$ months. The participants with slight to no willingness of drug abstention reported higher anxiety symptoms than those with significant willingness of drug abstention. The participants who had been to CDT two or more times had significantly $(P<0.01)$ more anxiety than those that were in CDT for the first time.

\section{Correlation of Anxiety Symptoms and Related Factors}

Table 2 shows the results of the correlation analyses between SAS scores and continuous variables. Age and perceived stress were significantly and positively correlated with SAS anxiety scores $(P$ $<0.01$ ). With respect to positive psychological capabilities, lower levels of optimism in participants (higher the LOT-R scores) correlated with higher the anxiety symptoms $(P<0.01)$.

\section{Hierarchical Multivariate Regression Predicting Anxiety Symptoms}

The HMR models of SAS score are shown in Table 3. Each block of the independent variables made a significant contribution to the variance of anxiety symptoms $(P<0.05)$. A total of $42.2 \%$ of variance was explained by the final regression model in anxiety symptoms. The $R^{2}$ changes indicated the incremental variance explained by the demographics characteristics, characteristics of drug use, characteristics of current rehabilitation, perceived stress and optimistic of variables were 5.7, 18.3, 1.8, 15.5, and $0.9 \%$, respectively. It was also indicated that the characteristics of drug use and perceived stress made the most significant contributions to the variance of anxiety symptoms.

The final HMR models revealed that age, educational level, types of drugs, willingness of drug abstention, period of time of current CDT, perceived stress, and optimism (LOR-T) were significant predictors of anxiety symptoms. The anxiety symptoms were significantly and positively associated with the age, period of current CDT, and perceived stress, yet significantly and inversely associated with optimism $(P<0.01)$. The study showed that perceived stress was the second highest contributor to anxiety symptoms (15.5\% of variation in the model being explained), and it was the most important associated factor for anxiety symptoms. The greater the perceived stress, the greater the anxiety symptoms were; however, optimism (with lower LOR-T score) correlated with a lower perceived anxiety and may play a role in attenuating anxiety symptoms. 
TABLE 2 | Correlation of SAS and related factors.

\begin{tabular}{|c|c|c|c|c|c|c|c|}
\hline & $\mathbf{M}$ & SD & 1 & 2 & 3 & 4 & 5 \\
\hline 1. Anxiety symptoms (SAS) & 45.23 & 11.698 & 1 & & & & \\
\hline 2. Age & 33.35 & 8.862 & $0.134^{\star \star}$ & 1 & & & \\
\hline 4. Perceived stress & 15.92 & 5.535 & $0.531^{\star \star}$ & 0.059 & $-0.228^{\star \star}$ & 1 & \\
\hline 5. Optimism (LOT-R) & 15.27 & 3.432 & $0.438^{\star \star}$ & 0.025 & $-0.264^{\star \star}$ & $0.507^{\star \star}$ & 1 \\
\hline
\end{tabular}

"significant at the 0.01 level (two-tailed); The higher LOT-R score indicating the low levels of optimism.

TABLE 3 | The hierarchical multiple regression models of anxiety symptoms.

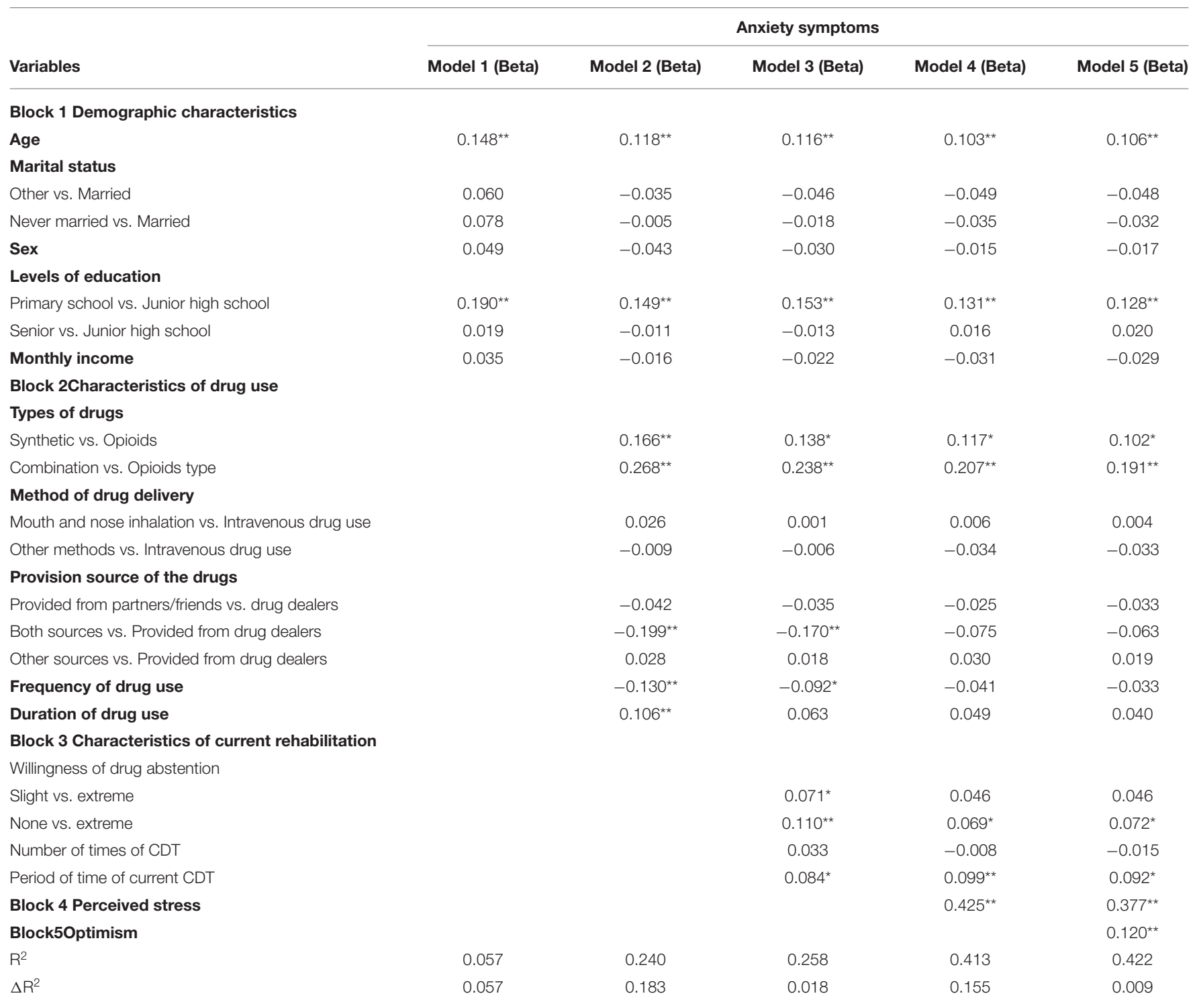

"Significant at the 0.05 level (two-tailed); "* Significant at the 0.01 level (two-tailed).

$C D T$, compulsory detoxification treatment. 


\section{DISCUSSION}

The results from this study indicated that anxiety symptoms were severe among the drug users undergoing CDT, with a prevalence of anxiety symptoms of $33.2 \%$, which is significantly higher than those of the general public (ranging from 13.6 to $28.8 \%$ ) $(28,29)$ and the patients attending methadone maintenance treatment in China (18.4-19.5\%) $(9,30)$. However, it was lower than reported levels of anxiety in Hispanic drug users in Puerto Rico (31), Brazilian LSD users (64.32\%) (32) and Chinese drug users with CDT in Yunnan (SAS = 52.32) (33). Age, levels of education, types of drugs, willingness of drug abstention, and perceived stress were predictors of anxiety symptoms. Furthermore, optimism may have played a positive role in attenuating the anxiety symptoms brought by CDT.

The characteristics of drug use were of the greatest importance in predicting anxiety symptoms, accounting for $18.3 \%$ of the total variance. The drug users who used synthetic drugs were more likely to suffer from anxiety symptoms, which were different results from a previous study that showed no significant differences in anxiety symptoms between drug users who used synthetic drugs and opioids (34). Given the shifting preference for synthetic drugs in China, as also seen in this study, it is important to realize the changing psychiatric comorbidities that now may be seen in drug users undergoing $\operatorname{CDT}(35,36)$. These changes may impact the approach taken in CDT, as well as the availability of mental health services to best help drug users through their journey to maintain abstinence.

In terms of characteristics of rehabilitation, willingness of drug abstention was a predictor of anxiety symptoms. Drug users who were extremely willing to abstain from drugs suffered from lower levels of anxiety symptoms than those with slight or no willingness. Personal subjective willingness and motivation may be essential for the successful treatment during the process of rehabilitation. The drug users who were extremely willing may actively cope with treatment through positive psychological capabilities, such as optimism, and take advantage of available resources, therefore, feeling less stressed and anxious. On the other hand, those that are much less willing to abstain from drugs are more prone to anxiety, and also have many of the risk factors for relapse after treatment, such as excessive dependence on drugs, lack of social support, relapse after several attempts of rehabilitation, or dissatisfaction with life after rehabilitation (37).

Perceived stress was the next most important predictor of anxiety symptoms. The results showed that the greater the perceived stress, the higher the prevalence of anxiety symptoms. CDT drug users generally perceive some degree of psychological stress, likely due to the loss of support, discrimination, and/or exclusion from their family members and society, as noted in a previous study (16). In addition, the environment of CDT itself may result in significant stress, given drug users are required or forced to engage in various activities and rehabilitation, which may or may not be desired by the individual. The drug users also have psychological barriers of returning to the society. They may worry about their failure of drug abstention, be selfaccusatory, feel guilty, and have difficulties in controlling their future lives, which could lead to their perceiving stress during CDT rehabilitation. Some may have experienced several attempts at drug abstention before returning to CDT, which compounds their vulnerability, feeling of pressure to succeed, or loss in confidence; therefore, leading to additional anxiety symptoms, as was shown in our population (38).

Optimism played a protective role in reducing anxiety symptoms. The more optimistic the drug users were, the less likely they were to have symptoms of anxiety. A study by Shen et al. in a CDT in China showed that a negative mood correlated with cravings for methamphetamine (39). It was obvious that interventions on optimism enhancement for drug users could help them reduce the prevalence of anxiety symptoms. Given that optimism has been shown to decrease cravings, improve willingness for abstinence, and improve long term outcomes, incorporation of mental health services in CDT that allow drug users to improve positive psychological capabilities would be helpful (20).

\section{LIMITATIONS}

This study exerts the limitation of being a cross-sectional design. Thus, conclusions about the causality between characteristics of drug and anxiety symptoms could not be derived. The faceto-face interview method is used to ensure the authenticity of the data; however, we are reliant on the quality of the recorded data. Besides, our study only assessed the related risk factors include drug users' demographic characteristics and characteristics of drug use, social support, stress and optimism without control group. The clinical information and unmeasured confounders need further study. However, the participants were selected with clustering sampling in three cities and the sampling size was large, which may allow for the generalizability to other populations.

\section{CONCLUSION}

The prevalence of anxiety symptoms among drug users undergoing CDT is high. Anxiety symptoms are effectively predicted by perceived stress of the drug user and types of drugs they have been using. Moreover, optimism was an important protective factor for attenuating anxiety symptoms which stemmed from CDT. Providing psychological counseling for drug users in CDT which targets the following areas could effectively improve the prevalence of anxiety symptoms: (1) teach coping skills and the adoption of positive psychological capabilities, including optimism; (2) teach techniques to manage perceived stress; and (3) improve support programs for life after release from CDT.

\section{DATA AVAILABILITY STATEMENT}

The datasets generated for this study are available on request to the corresponding author. 


\section{ETHICS STATEMENT}

The studies involving human participants were reviewed and approved by the ethics committee of China Medical University. The patients/participants provided their written informed consent to participate in this study.

\section{AUTHOR CONTRIBUTIONS}

$\mathrm{XY}$ designed the study and provided input on the original research plan, analysis and interpretation of data and wrote the first draft of the manuscript. YW and SY contributed to the acquisition of subjects and conduction of the survey. CK contributed to the revision the manuscript. All authors have contributed to and approved the final manuscript.

\section{REFERENCES}

1. Office of the National Narcotics Control Commission. Annual Report on Drug Controlin China. (2016).

2. Yang M, Mamy J, Gao P, Xiao S. From abstinence to relapse: a preliminary qualitative study of drug users in a compulsory drug rehabilitation center in Changsha, China. PLoS ONE. (2015) 10:e0130711. doi: 10.1371/journal.pone.0130711

3. Xiong H, Jia J. Situational social support and relapse: an exploration of compulsory drug abuse treatment effect in China. Int J Offender Ther Comp Criminol. (2019) 63:1202-19. doi: 10.1177/0306624X18815243

4. Sarah Hunter B, Katie W, Watkins KW, Paddock SM, Hepner KA. The moderating effects of group cognitive behavioral therapy for depression among substance users. Psychol Addict Behav. (2012) 26:906-16. doi: 10.1037/a0028158

5. Merikangas KR, Mehta RL, Molnar BE, Walters EE, Swendsen JD. Comorbidity of substance use disorders with mood and anxiety disor-ders: results of the International Consortium in Psychiat-ric Epidemiology. Addict Behav. (1998) 23:893-907. doi: 10.1016/S0306-4603(98)0 0076-8

6. Liu L, Hsiao SC. Chinese female drug users' experiences and attitudes with institutional drug treatment. Int J Offender Ther Comp Criminol. (2018) 62:4221-35. doi: 10.1177/0306624X18758894

7. Dong H, Yang M, Liu L. Comparison of demographic characteristics and psychiatric comorbidity among methamphetamine-, heroin- and methamphetamine-heroin co- dependent males in Hunan, China. BMC Psychiatry. (2017) 17:183. doi: 10.1186/s12888-017-1346-7

8. Yang J, Giummarra MJ. Compulsory and voluntary drug treatment models in China: a need for improved evidence-based policy and practice to reduce the loaded burden of substance use disorders. Int J Drug Policy. (2020) 7:103063. doi: 10.1016/j.drugpo.2020.103063

9. Yin W, Pang L, Cao X, McGoogan JM, Liu M. Factors associated with depression and anxiety among patients attending community-based methadone maintenance treatment in China. Addiction. (2015) 1:51-60. doi: 10.1111 /add. 12780

10. Lazarus RS, Folkman S. Stress, Appraisal, and Coping. New York, NY: Springe. (1984).

11. Etchin AG, Fonda JR, McGlinchey RE, Howard EP. Toward a system theory of stress, resilience, and reintegration. ANS Adv Nurs Sci. (2020) 43:75-85. doi: 10.1097/ANS.0000000000000277

12. Kong DT, Jolly PMA. stress model of psychological contract violation among ethnic minority employees. Cultur Divers Ethnic Minor Psychol. (2019) 25:424-38. doi: 10.1037/cdp0000235

13. Gieselmann A, Elberich N, Mathes J, Pietrowsky R. Nightmare distress revisited: cognitive appraisal of nightmares according to Lazarus' transactional model of stress. J Behav Ther Exp Psychiatry. (2020) 68:101517. doi: 10.1016/j.jbtep.2019.101517

\section{FUNDING}

The research on AIDS high risky sexual behavior and risk prediction among Male-to-Female Transgender individuals, funded by National Natural Science of Foundation of China, 81302475, http://isisn.nsfc.gov.cn/egrantindex/funcindex/prj search-list, XY.

\section{ACKNOWLEDGMENTS}

The authors thank Liaoning Juveniles Compulsory Drug Detention and Detoxification center, which gave much help for this study. The author also thanks the drug users who shared their inner experiences for this study.

14. Pahayahay A, Khalili-Mahani N. What media helps, what media hurts: a mixed methods survey study of coping with COVID-19 using the media repertoire framework and the appraisal theory of stress. J Med Internet Res. (2020) 22:e20186. doi: 10.2196/20186

15. Alabau AC, Isabel JAC, Rodríguez CA. Perceived stress related to methadone withdrawal. Psicothema. (2016) 28:235-40. doi: 10.7334/psicothema2015.164

16. Pérodeau GM, Guillaume GF. Psychotropic drug use and the relation between social support, life event and mental health in the elderly. J Appl Gerontol. (2000) 19:23-41. doi: 10.1177/073346480001900102

17. Swindle RW, Cronkite RC, Moos RH. Life stressors, social resources, coping, and the 4-year course of unipolar Depression. J Abnormal Psychol. (1989) 8:468-77. doi: 10.1037/0021-843X.98.4.468

18. Vuong T, Ritter A, Shanahan M, Ali R, Nguyen N, Minh KP. Quality of life as a predictor of time to heroin relapse among male residents following release from compulsory rehabilitation centres in Vietnam. Drug Alcohol Rev. (2020) 40:296-306. doi: 10.1111/dar.13176

19. John PF, Jefferson DP, Carlos GF. Anxiety sensitivity, controllability, experiential avoidance and their relation to drug of choice and addiction severity in a residential sample of substance-abusing veterans. Addict Behav. (2003) 28:851-70. doi: 10.1016/S0306-4603(02)00216-2

20. Carver CS, Scheier MF. Dispositional optimism. Trends Cogn Sci. (2014) 18:293-9. doi: 10.1016/j.tics.2014.02.003

21. Brown BS, O'Grady K, Battjes RJ, Farrell EV. Factors associated with treatment outcomes in an aftercare population. Am J Addict. (2004) 13:44760. doi: 10.1080/10550490490512780

22. Zung WWK. A rating instrument for anxiety disorders. Psychosomatic. (1971) 12:371-9. doi: 10.1016/S0033-3182(71)71479-0

23. Xu JP, Wei Y. Social support as a moderator of the relationship between anxiety and depression: an empirical study with adult survivors of Wenchuan earthquake. PLoS ONE. (2013) 8:e79045. doi: 10.1371/journal.pone.0079045

24. Cohen S, Kamarck T, Mermelstein R. A global measure of perceived stress. J Health SocBehav. (1983) 24:385-96. doi: 10.2307/2136404

25. Scheier MF, Carver CS, Bridges MW. Distinguishing optimism from neuroticism (and trait anxiety, self-mastery, and self-esteem: a reevaluation of the Life Orientation Test. J Pers Soc Psychol. (1994) 67:1063-78. doi: 10.1037/0022-3514.67.6.1063

26. Moyer CA, Ekpo G, Calhoun CL, Greene J, Naik S. Quality of life, optimism/pessimism, and knowledge and attitudes toward HIV Screening among pregnant women in Ghana. Women Health Issues. (2008) 18:301-9. doi: 10.1016/j.whi.2008.02.001

27. Preacher KJ, Hayes AF. Asymptotic and resampling strategies for assessing and comparing indirect effects in multiple mediator models. Behav Res Methods. (2008) 40:879-91. doi: 10.3758/BRM.40.3.879

28. Alonso J, Angermeyer MC, Bernert S, Bruffaerts R, Brugha TS. Prevalence of mental disorders in Europe: results from the European Study of the Epidemiology of Mental Disorders (ESEMeD) project. ActaPsychiatrScand Suppl. (2004) 420:21-7. doi: 10.1111/j.1600-0047.2004.00327.x 
29. Kessler RC, Berglund P, Demler O, Jin R, Merikangas KR. Lifetime prevalence and age-of-onset distributions of DSM-IV disorders in the National Comorbidity Survey Replication. Arch Gen Psychiatry. (2005) 62:593-602. doi: 10.1001/archpsyc.62.6.593

30. Jiao M, Gu J, Xu HF. Resilience associated with mental health problems among methadone maintenance treatment patients in Guangzhou, China. AIDS Care-Psychol Soc Med Aspects AIDS/HIV. (2017) 29:660-5. doi: 10.1080/09540121.2016.1255705

31. Reyes JC, Robles RR, Colón HM, Marrero CA, Matos TD. Severe anxiety symptomatology and HIV risk behavior among Hispanic injection drug users in Puerto Rico. AIDS Behav. (2007) 11:145-50. doi: 10.1007/s10461-006-9090-x

32. Remy LS, Scherer J, Guimarães L, Surratt HL, Kurtz SP. Anxiety and depression symptoms in Brazilian sexual minorityecstasy and LSD users. Trends Psychiatry Psychother. (2017) 39:239-46. doi: 10.1590/2237-6089-2016-0081

33. Lin Y, Zhang T, Yang C, Zhou M, Zhang H. Mental health situation analysis of 418 drug addicts in compulsory addiction treatment center with SDS and SAS. J Dermatol Venereol. (2011) 33:1-3. doi: 10.3969/j.issn.1002-1310.2011.01.001

34. Tatalović VS, Dadić-Hero E, RuŽić K. The relationship between personality traits and anxiety/depression levels in different drug abusers' groups. Ann Ist Super Sanita. (2013) 49:365-9. doi: 10.4415/ANN_13_04_08

35. Rech MA, Donahey E, Cappiello Dziedzic JM, Oh L, Greenhalgh E. New drugs of abuse. Pharmacotherapy. (2015) 35:189-97. doi: 10.1002/phar.1522

36. Li GJ, Li Na, Zheng WH, Wang QL. Comparative study on psychological and behavioral characteristics between "new drug" abusers and “traditional drug" abusers. Chin J Drug Depend. (2011) 20:126-30 doi: 10.13936/j.cnki.cjdd1992.2011.02.001

37. Zhou C, Deng JP, Li WP. Relapse factors among drug abusers after voluntary drug treatment and rehabilitation through labor. Chinese J Drug Dependence. (2011) 20:131-5. doi: 10.1007/s10008-0101224-4

38. Temple EC, Driver M, Brown RF. Cannabis use and anxiety: is stress the missing piece of the puzzle? Front Psychiatry. (2014) 24:168. doi: 10.3389/fpsyt.2014. 00168

39. Shen W, Liu Y, Li L, Zhang Y, Zhou W. Negative moods correlate with craving in female methamphetamine users enrolled in compulsory detoxification. Subst Abuse Treat Prev Policy. (2012) 30:7-44. doi: 10.1186/1747-59 $7 \mathrm{X}-7-44$

Conflict of Interest: The authors declare that the research was conducted in the absence of any commercial or financial relationships that could be construed as a potential conflict of interest.

Copyright (c) 2021 Yang, Kovarik, Wang and Yu. This is an open-access article distributed under the terms of the Creative Commons Attribution License (CC BY). The use, distribution or reproduction in other forums is permitted, provided the original author(s) and the copyright owner(s) are credited and that the original publication in this journal is cited, in accordance with accepted academic practice. No use, distribution or reproduction is permitted which does not comply with these terms. 